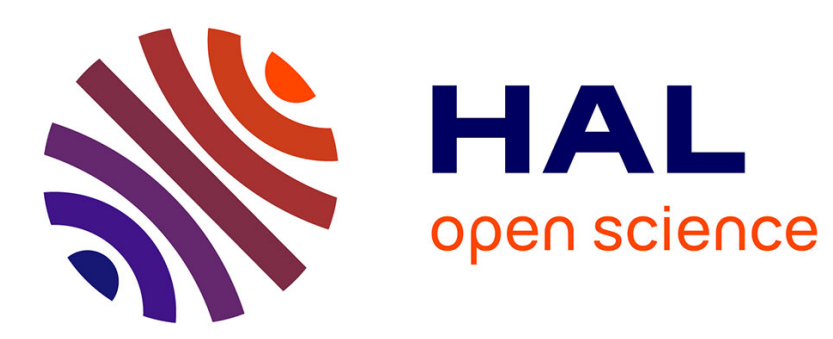

\title{
Modeling performance and information exchange between fishing vessels with artificial neural networks
}

\author{
Michel Dreyfus-Leon, Daniel Gaertner
}

\section{To cite this version:}

Michel Dreyfus-Leon, Daniel Gaertner. Modeling performance and information exchange between fishing vessels with artificial neural networks. Ecological Modelling, 2006, 195, pp.30-36. ird-00269193

\section{HAL Id: ird-00269193 \\ https://hal.ird.fr/ird-00269193}

Submitted on 14 May 2008

HAL is a multi-disciplinary open access archive for the deposit and dissemination of scientific research documents, whether they are published or not. The documents may come from teaching and research institutions in France or abroad, or from public or private research centers.
L'archive ouverte pluridisciplinaire HAL, est destinée au dépôt et à la diffusion de documents scientifiques de niveau recherche, publiés ou non, émanant des établissements d'enseignement et de recherche français ou étrangers, des laboratoires publics ou privés. 


\title{
Modeling performance and information exchange between fishing vessels with artificial neural networks
}

\author{
Michel Dreyfus-Leon ${ }^{a, b, *}$, Daniel Gaertner ${ }^{c}$ \\ ${ }^{a}$ Instituto Nacional de la Pesca-PNAAPD, México \\ ${ }^{b}$ Facultad de Ciencias Marinas, UABC, México \\ ${ }^{c}$ Institut de Recherche pour le Développement (IRD), UR 109 CRHMT, Av. Jean Monnet, BP 171, 34203 Sète \\ Cedex France
}

\begin{abstract}
A fishery is simulated in which 20 artificial vessels learn to make decisions through an artificial neural network in order to search for schools of fish among the available fishing grounds. Three scenarios with different degree of variability, including uncertainty in the searching process, are considered. The simulation model accounts for the main features commonly observed in a purse seine tuna fishery in a time and a space scales. Vessel strategies are chosen by the artificial neural network, on the basis of the following decision criteria: information concerning time searching in a specific area, previous performance in this area, knowledge of the quality of surrounding fishing grounds, presence of other vessels fishing actively and trip length. An analysis of the effects of sharing information between vessels is done and this was compared to individual artificial fishing vessels. In general a group of fishing vessels shows higher performance than individual vessels. A convex performance comparison curve for several group sizes is found in all scenarios considered. The optimum group size differs according to the variability of the artificial world. At bigger group sizes performance decreases, probably due to competition and depletion effects of some fishing grounds.
\end{abstract}

Key words: artificial neural networks, individual based model, yellowfin tuna, fishery performance, information-sharing.

\section{Introduction}

Because fishing effort magnitude and distribution is closely related to fishing mortality, recognizing the fleet dynamics as a responsive component of the fishery system is a key issue in stock assessment studies. Nevertheless most fishery models lack the strength to include human behavior, particularly learning as a way to adapt the response strategy and, consequently a fundamental factor in the modeling process. Most models include fishing effort in order to build specific rules for moving to nearby areas but only as an aggregate variable and in response to local changes in abundance (Mangel and Clark, 1983; Allen and McGlade, 1986; Hilborn and Walters, 1987).

Several studies intended to understand fishermen behavior at sea with the aid of observer data (Gillis et al., 1993; Gaertner et al., 1999) or using simulated data in an individual based modeling approach (Millischer, 2000). However, excepting the study by Dreyfus-Leon (1999), learning has not commonly been considered in fishery studies.

It must be emphasized that for fishery management it is important to know how the fleets will adjust to changing circumstances because fishermen adapt to regulations in ways that managers cannot predict. Another important aspect in several search-based fisheries, such as tuna purse-seine fisheries, is communication and sharing information between groups of fishermen (vessels).

* Corresponding author. Present address: PMB-070, P.O. Box 189003, Coronado, CA 92178-9003, USA. E-mail addresses: dreyfus@cicese.mx (M. Dreyfus-Leon), gaertner@ird.fr (D. Gaertner). 
In this study we present a framework for analyzing the efficiency of information sharing in distributed-search process such as a tuna purse seine fishery. We use this model to compare search success between vessels with and without information sharing under several regimes of resource variation. The decision-making behavior of the vessels is simulated with the aid of an artificial neural network (ANN) which seems an ideal tool to represent fishermen behavior at sea as well as the decision making process when searching for the resource. The artificial fishermen, "fishermat", hereafter in relation to the term animat used frequently in behaviour-based artificial intelligence field (Maes, 1993), decide independently in which area or fishing ground they will allocate their effort. A comparison of the performance between a group that share information and independent artificial fishermen is performed in three scenarios with fishing grounds differing in variability in two terms: location and fish density. These two factors create different levels of uncertainty in fish searching operations.

\section{Methodology}

\subsection{Simulated world}

A simulated world (Fig. 1) with 25 areas of $50 \times 50$ pixels is used for the analysis. Some of those areas can be potential fishing grounds. Fish recruitment is considered at the beginning of each simulated year. Areas of high, medium and low fish density receive each $25 \%, 16.66 \%$ and $8.33 \%$ respectively of the total annual recruitment.

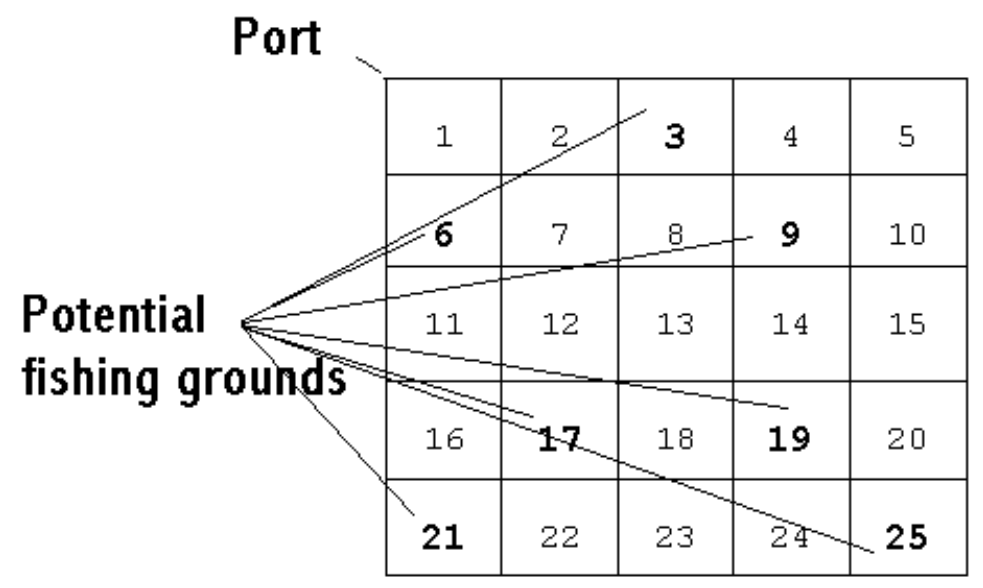

Fig. 1. Simulated world.

Three scenarios with different degrees of recruitment variability among the fishing grounds are simulated. In scenario I, only fish density among 2 of the 6 potential fishing grounds changes over time with a 0.2 probability. In scenario II the probabilities of recruitment levels are the same than those for scenario I, except that recruitment disappears from one of the fishing grounds to appear in a nearby area ( 0.2 probability level). Scenario III has a mixture of the attributes of scenarios I and II, therefore presents more variability ( 0.2 probability level). The attributes of each scenario are described in table 1.

Tuna schools are considered as individual entities of 8 tons each that can move at random within a fishing ground without the possibility of moving elsewhere. Since each pixel represents $6 \times 6$ nautical miles, according to previously reported tuna speed (Edwards and Kleiber, 1989), schools move every 6 hours in the simulation process.

Twenty vessels are considered in each simulated scenario, some fish independently and others form a group that share information. They all depart from the same port (upper left corner in Fig. 1). Vessels stay in port a time assigned at random (between 10 and 20 days, as observed in tuna fisheries). Movement is performed in an hourly basis and trip duration is fixed at 45 days. Day and night are also considered in the model. If a vessel searching (only during daytime) has the same position of a tuna 
school, the vessel detects this and the fishing is performed (it is assumed that the school is caught by the vessel). This means that vessels stay in the same position for 3 hours (to take this into account the setting time) as observed in real fisheries. When a vessel is searching in a particular area, movement is at random.

Table 1. Fishing grounds considered in the three scenarios. $\mathrm{H}$ (high fish density), $\mathrm{M}$ (medium fish density), $\mathrm{L}$ (low fish density). Column A presents fish density levels in the fishing grounds due to the amount of recruitment with a 0.8 probability of occurrence. Columns B, C and D show conditions in the three scenarios respectively with a 0.2 probability of occurrence.

\begin{tabular}{lllll}
\hline $\begin{array}{l}\text { Fishing } \\
\text { ground }\end{array}$ & $\begin{array}{l}0.8 \text { probability } \\
\text { in all scenarios }\end{array}$ & $\begin{array}{l}\text { Scenario I } \\
0.2 \text { probability }\end{array}$ & $\begin{array}{l}\text { Scenario II } \\
0.2 \text { probability }\end{array}$ & $\begin{array}{l}\text { Scenario III } \\
0.2 \text { probability }\end{array}$ \\
\hline Area 3 & H & M & H & M \\
Area 6 & L & L & L & $\mathrm{L}$ \\
Area 9 & M & H & M & H \\
Area 17 & M & M & M & M \\
Area 19 & H & H & - & - \\
Area 21 & L & L & L & $\mathrm{L}$ \\
Area 25 & - & - & $\mathrm{H}$ & $\mathrm{H}$ \\
& & & & \\
\hline
\end{tabular}

When night periods start, and if the vessel has been searching during daytime at least for 12 hours, fishermat decides whether to move to a different area or stay in the present one. This decision is done by an ANN, which has been previously trained. If the fishermat decides to keep searching in the same area it stays at a fixed position, but if it decides to move elsewhere, it keeps moving day and night until the vessel enters the selected area.

\subsection{Artificial neural network}

Fishermen behavior in terms of movement decision (i.e., when and where to move) is modeled with the aid of an ANN. Factors affecting the decision to move constitute the input layer of the ANN (Fig. 2). All the knowledge used by the ANN is measured with ordinal variables (i.e., categorical variables with ordered levels): its performance in economic terms and the time spent searching. The ANN also uses his knowledge of the length of the fishing trip for decision-making, as well as an update at each time step of the fishermat own perception about the richness of the area visited. The ANN compares this information with its knowledge of all the other fishing grounds and updates the information of the quality of the fishing grounds. Notice that this factor is the only variable, which differs at the input layer of the ANN, used to simulate the decisions taken by the two categories of fishermat compared in this study (individual vs. group). Consequently, the judgment of individual fishermat about the suitability of each area results only from their own history in the fishery. In contrast, at each time step fishermat forming a group exchange information and share knowledge on the richness of different locations. The decision to move can be seen as an opportunity cost and closely depends on the duration of the running time (that is, the time devoted to move from an area to another without actively searching for fish signs). In this simulation, fishermats were not allowed to catch fish if found during the navigation time between areas. Memory of the last three decisions was also kept as information for the fishermat. The input layer is completed by a factor indicating the presence (yes/no) of other vessels fishing in the same area. Purse-seine observers commonly describe this "spying" activity and we assume that this attitude has an influence on fishermen decisions to move. Table 2 summarizes the factors involved in the decision to move as well as how they were encoded in the ANN.

The size of the hidden layer with six neurons was chosen during training runs of the model based on vessel performance. At the output layer, four neurons predict benefits or costs of each possible decision: stay in the same area or move to the best one nearby, mid-distant or far away area. The decision-action taken is the one with higher predicted benefits (or less costs). 


\section{Movements of the vessel}

$\begin{array}{cccc}\text { Same } & \text { Nearby } & \text { Mid-distant } & \text { Far away } \\ \text { area } & \text { area } & \text { area } & \text { area }\end{array}$

$\nwarrow$

$\bigcirc$

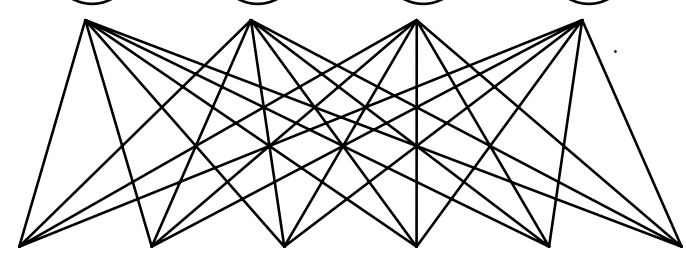

1<smiles>C1CCCC1</smiles>

$\uparrow$<smiles>c1ccccc1</smiles><smiles>CCC[13CH3]</smiles>

$\bigcirc$

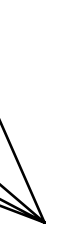

$\bigcirc$
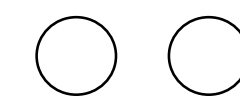

00

Hidden layer

Output layer

(When and where

to move)
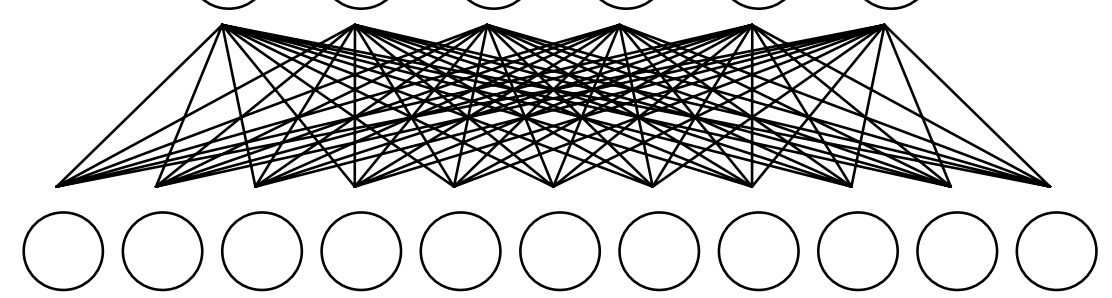

Input layer

(Factors affecting the decision choice)

Fishermat's perception about the richness of the actual fishing area

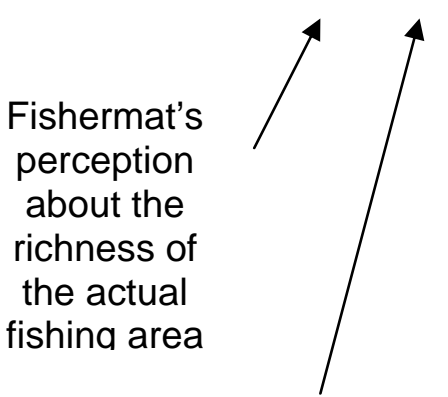

Previous success in the fishing area

Cumulative searching time in the same area

Information about the richness of the other fishing grounds

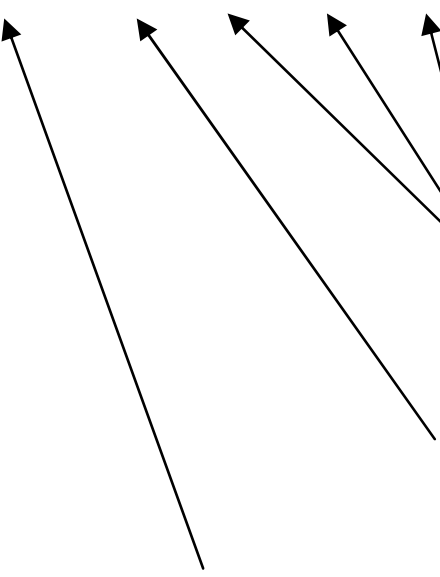

Length of the fishing trip
Memory of the closest previous decisions

Observation of other vessels in fishing activity in the same area

Fig. 2. Artificial neural network architecture. 
Table 2. Factors affecting the decision to move (input layer) and codification.

\begin{tabular}{|c|c|}
\hline Input Variable & Values \\
\hline Performance in the present fishing area. & Losses or gains (7 categories) \\
\hline Time searching in the present fishing area. & Starting the search, ...to long time searching in the area (4 categories) \\
\hline Duration of the fishing trip. & Starting the fishing trip, ...to final days of the fishing trip. \\
\hline Richness of the present fishing area. & Very bad,...to very good quality (5 categories) \\
\hline Richness of the best nearby area. & Very bad,...to very good quality (5 categories) \\
\hline Richness of the best mid-distant area. & Very bad,...to very good quality (5 categories) \\
\hline Richness of the best far away area. & Very bad,...to very good quality (5 categories) \\
\hline Movement decision $\mathrm{t}-1$. & Stay in same area or move to another fishing area (4 categories) \\
\hline Movement decision t-2. & Stay in same area or move to another fishing area (4 categories) \\
\hline Movement decision t-3. & Stay in same area or move to another fishing area (4 categories) \\
\hline \multicolumn{2}{|c|}{ Presence of other vessels fishing in the area. Yes/no } \\
\hline
\end{tabular}

Neural networks have not commonly been used in fishermen behaviour studies. One exception is the study by Dreyfus-Leon (1999), which is devoted to the analysis of fishermen search behaviour. This model was built with two neural networks which mimic two separate decision-making processes in fishing activities: (a) the decision to move to a new fishing ground or to stay in the same area and (b) the search for fish schools within the fishing area. Our approach differs from this latter study. Since our goal is to analyse communication and information exchange related to decisions of moving between fishing grounds, using another neural network for local movement could have an effect on performance. Instead, search movement within a fishing ground is considered a random search. For the same reasons, fish schools move at random, avoiding the clustering of fish in relation to particular habitat conditions. By these means we tried to ensure that "luck", while searching in an area would not be a factor affecting performance, thereby misleading the results.

\subsection{Learning}

The ANN is trained with standard backpropagation methodology and reinforcement learning, which seems to be a good strategy to mimic human behavior when combined with the rewarding actions of neural networks that promote higher fitness (Bonarini, 1997). Reinforcement learning is tantalizing because learning occurs through trial and error experimentation within the environment. Feedback is a scalar payoff, hence no explicit teacher is required, and little or no prior knowledge is needed (Whitehead and Lin, 1995). Besides, learning is the essential adapting tool for humans and, in complex and variable environments; learning allows the possibility of prompt adjustment (DreyfusLeon, 1999). Reward and punishment are scalar values related to benefits and costs of fishing operations of the purse seine tuna fishery in the Eastern Pacific Ocean. One hundred runs were performed in search for the optimum artificial neural network. The best one is used to compare performance without further learning.

\section{Results}

Twenty replicate runs, with group sizes composed with 2-12 artificial vessels each, were performed in all scenarios. The rest of the vessels (to add up to 20) were fishing on their own. The major difference in the replicate runs is due to random fish abundance and distribution variations. Fig. 3 depicts the difference between the mean trip performances, measured as the number of tuna schools caught per trip of the two types of artificial vessels (group versus individual).

The relative performance increases with group size, reaching an optimum at the 10-vessels group size in scenarios I and II. Beyond this threshold, increasing the group size leads to a decline in the efficiency of the grouped fishermen. In the case of scenario III, the group performance increases even at a group size of 12 artificial vessels. An increase in performance of grouped fishermats as compared to individual fishermats is seen at all group sizes from scenario I to scenarios II and III. A " $\mathrm{t}$ " student test between grouped and individual fishermats shows significant differences in 
performance $(\mathrm{P}<0.01)$ starting at a group size of 8,6 and 4 fishermats respectively in scenarios I, II and III.

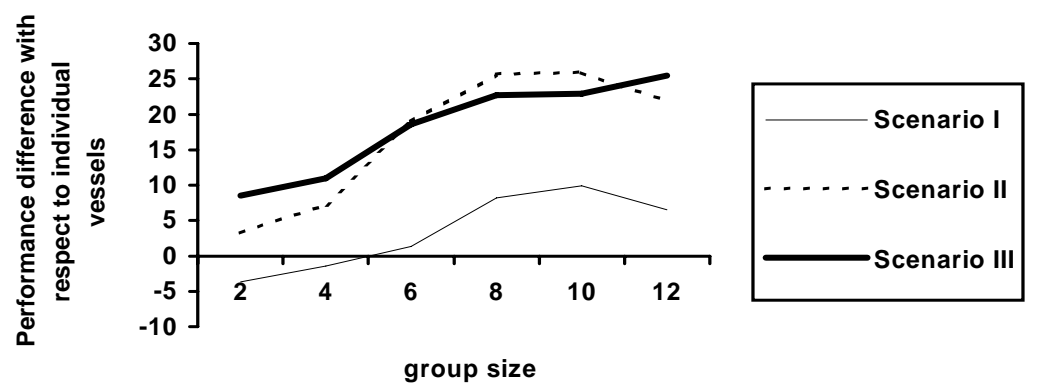

Fig. 3. Performance difference between group sharing information with respect to the cpue of individual artificial vessels.

An example of the minimum time needed to sample all fishing grounds by artificial vessels belonging to the group (sizes 2,4,6,8,10 and 12) is shown in Fig. 4. As the group size increases, the time to explore all areas decreases exponentially.

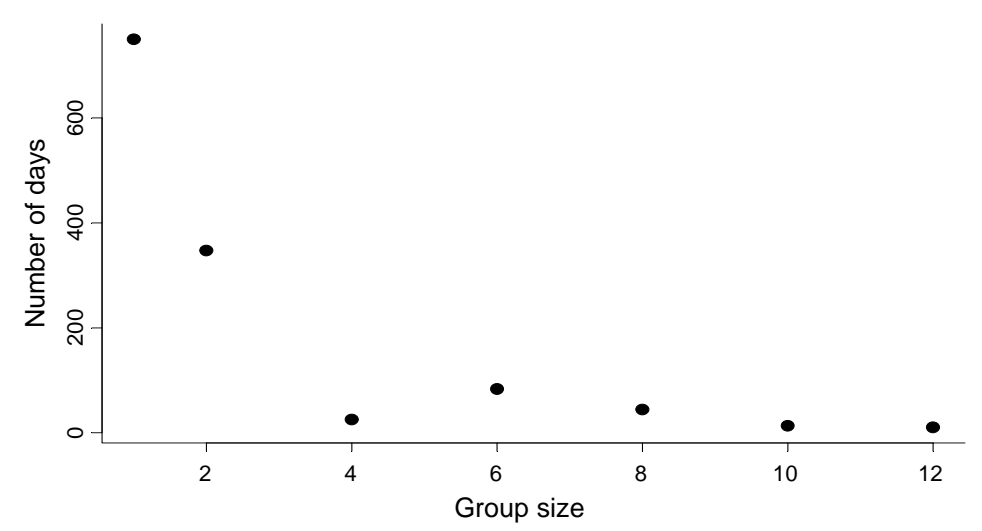

Fig. 4. Number of days needed to explore all fishing grounds in relation to group size.

With an optimum size of 10 vessels for the group sharing information, an account of vessels fishing in an area is done. In Fig. 5, data are taken from an area with sporadic high fish density in scenario III.

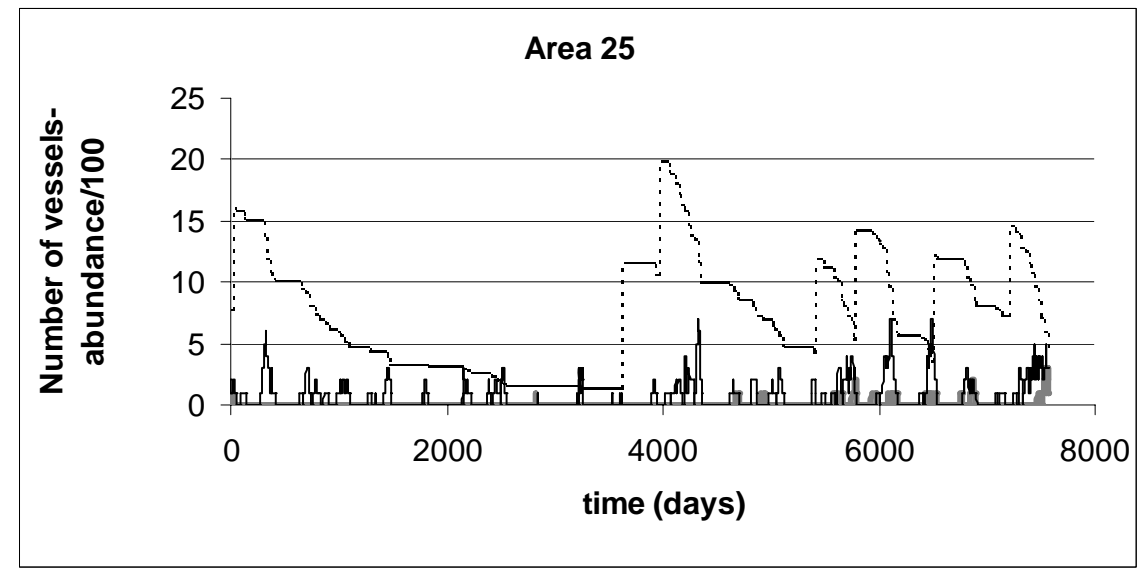

Fig. 5. Fishing effort in an area with sporadic high recruitment. Fish school abundance (dotted line), fishing effort by vessels sharing information (black line), fishing effort by independent vessels (gray line). 
As recruitment occurs, vessels belonging to the group start moving in and profit from higher fish abundance, while as density decreases the opposite occurs. With independent artificial vessels there is no particular trend in the number of vessels in the fishing area.

Catch per unit effort (CPUE) was calculated for all scenarios and a group-size of 10 artificial vessels. Days searching are used as a measure of fishing effort and CPUE is used as a performance index. In scenario I there is a similarity in performance over the 11-year series (Fig. 6a) and fishing efficiency (defined as the CPUE ratio of individual to information-sharing vessels) is close to 1 . In the other two scenarios CPUE tend to be different and the fishing efficiency is lower than one, marking a higher difference in performance between the two types of artificial vessels (Fig. 6b and 6c).

\section{A) Case 1}

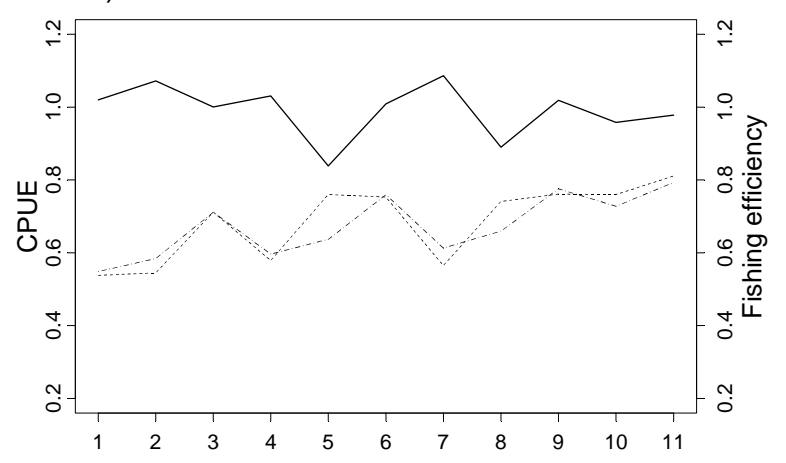

B) Case 2

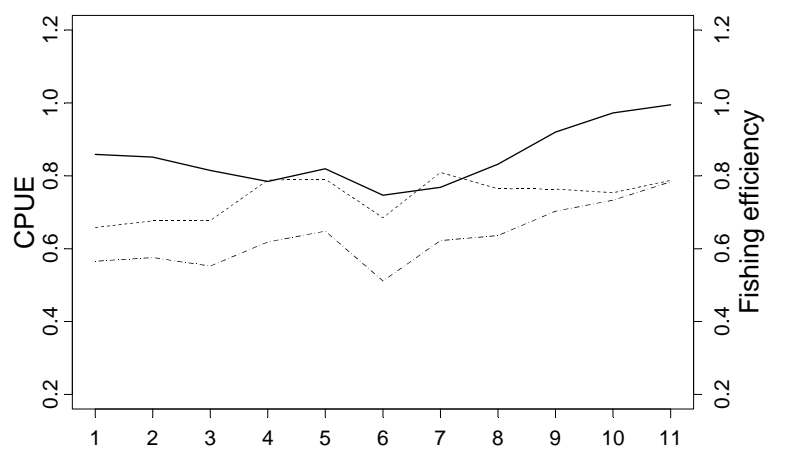

C) Case 3

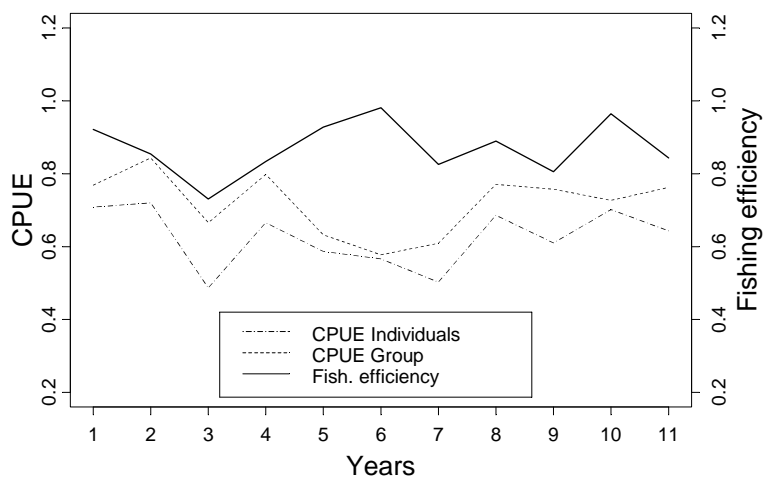

Fig. 6. Individual and group CPUE, as well as fishing efficiency for an 11-year run in scenario I (Case a), II (Case b) and III (Case c).

The time spent searching by artificial vessels in the three scenarios (Fig. 7) shows different patterns between individual and group vessels in scenarios with higher variability. There is a general tendency to search closer to port in all scenarios. Nevertheless it can be seen that the group sharing information profits from areas far from port, although costs could increase, when high fish abundance 
was present in those areas. This was also true for low level recruitment areas, since less fishing effort increased over time fish density, (i.e., scenario III, area 21).

Individuals

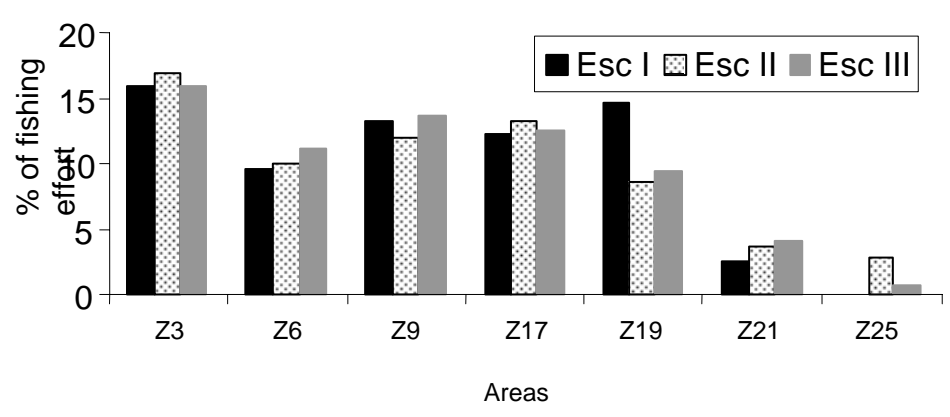

Group

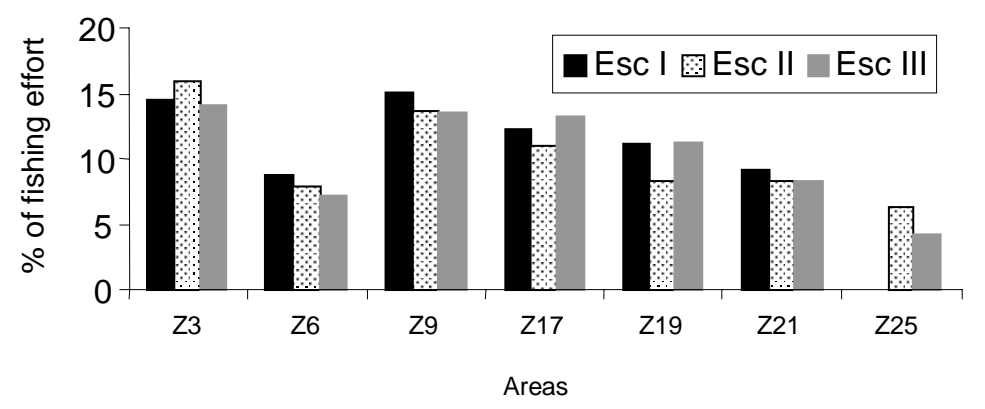

Fig. 7. Fishing effort distribution of individual fishermats (a) and grouped fishermats (b) among the fishing grounds in the simulated scenarios.

\section{Discussion and conclusion}

The input data used in this work seems a major improvement in fishermen behavior modeling with ANN compared to Dreyfus-Leon (1999), since memory of decisions and knowledge of the area quality was taken into account, as well as performance, time searching in a fishing ground, duration of the fishing trip and presence of other vessels were also considered.

In previous models, fishing grounds were considered independently of the location of the vessel (Dreyfus, 1999; Dreyfus and Kleiber, 2001) whereas in this model the position of the areas are considered in relative terms to the current position of the artificial fishing vessel. This variation allows for a generalized model that does not require a change in the ANN to be used in different environments and has more input variables that are considered important in the decision process by knowledgeable fishermen.

Care was taken to consider real fishing practices and to calibrate model parameters to reflect reality wherever possible.

Although the capacity of exchanging information between fishermats appears as a relevant factor for search decision-making, other variables could be considered in future analysis, such as diesel availability and awareness of some type of regulation (for example, time-area closure). This implies that a time (year-station) perception would need to be incorporated as a new input to the ANN.

Future developments of this approach would require that temporal variations of the resource knowledge, and the way fishermats handle information coming from other vessels be also studied in detail. Fuzzy logic can be incorporated as a mean to achieve that.

One limitation of our approach is due to the fact that the decision-making framework is the same for all individuals belonging to the same type of fishermen. For this reason searching behavior, which embodies fishing customs, traditions, folk knowledge, appears more societal than individual. 
Another interesting aspect for research would be to model different type of fishermen, risk-prone and risk-averse, explorers or exploiters.

From this study it appears that the advantages of belonging to a sharing information group in the real world would be high, especially under some degree of uncertainty related to the distribution and density of fishing resources at sea as seen particularly in scenarios II and III. In these simulations this was also evident as shown by the fact that many of the group vessels exploited high fish density areas close to a peak in fish abundance and several of those vessels started to move elsewhere when fish density decreased. Individual fishing vessels never get concentrated in those high-density areas.

In scenario I the difference in performance between the two types of fishermat was evident only when the group was composed of at least 8 artificial vessels. Nevertheless, the differences were small in that scenario, as confirmed by the fact that the CPUEs were similar and the fishing efficiency close to 1.

Since sharing information reduces the time to sample all potential fishing grounds and the acquisition of some knowledge of actual conditions of the resources, belonging to a group can also be considered a risk-averse strategy of fishermen. The optimum group size seems to depend on uncertainty levels, fish density and the extent of fishing grounds.

The decline in performance of groups with more than 10 grouped vessels in scenarios I and II may be due to a depletion of a local biomass, competitive interference among fishing vessels, or both. Such a "depletion-competition effect" has been commonly observed in the real world, specifically in the analysis of the non-linear relationship between local biomass and catch rates in tuna purse seine fisheries (Fonteneau et al., 1999), in trawler fisheries (Gillis et al., 1993; Rijnsdorp et al., 2000) or taken into account in simulation studies (Mangel and Beder, 1985).

Notice that CPUE is traditionally used in fisheries as an abundance index, but the effects or possible biases in CPUE due to communication between fishermen has to be evaluated (e.g., vessels belonging to a group tend to concentrate in higher fish density areas although total fish abundance can be low, thus creating a bias in CPUE estimates).

The search preference in fishing grounds closer to port in this model has been described previously in ANN models (Dreyfus-Leon, 1999), in bio-economical model accounting for fishing costs (Sampson, 1991), as well as in real fisheries (Eales and Wilen, 1986; Salas, 2000; Van Oostenbrugge et al., 2001).

Fishermen decision-making is a fundamental characteristic that has not been studied substantially and that must be incorporated in fishery models specially related to fishing effort distribution in order to study regulatory impacts on the fishing resources as well as to the industry. Artificial neural networks are some of the tools that allow this possibility.

\section{Acknowledgements}

This work was developed in part during a research-stay of the first author in the "Institut de Recherche pour le Développement”(IRD), Montpellier France.

\section{References}

Allen, P.M. and McGlade, J.M., 1986. Dynamics of discovery and exploitation: the case of the scotian shelf groundfish fisheries. Can. J. Fish. Aquat. Sci. 43, 1187-1200.

Bonarini, A., 1997. Anytime Algorithms. Adapt. Behav. 5 (3/4), 281-315.

Dreyfus-Leon, M.J., 1999. Individual-based modelling of fishermen search behaviour with neural networks and reinforcement learning. Ecol. Modelling, 129 (1-3), 287-297.

Dreyfus, M. and Kleiber, P., 2001. A spatial individual behaviour-based model approach of the yellowfin tuna fishery in the eastern Pacific Ocean. Ecol. Modelling, 146, 47-56.

Eales, J. and Wilen, J.E., 1986. An examination of fishing location choice in the pink shrimp fishery. Mar. Resource Economics, 2(4), 331-351.

Edwards, E.F. and Kleiber, P., 1989. Effects of nonrandomness on line transect estimates of dolphin school abundance. Fish. Bull. 87, 859-876. 
Fonteneau, A., Gaertner, D. and Nordstrom, V., 1999. An overview of problems in the catch per unit of effort and abundance relationship for the tropical purse seine fisheries. Coll. Vol. Sci. Pap. ICCAT, 49 (3), 258-278.

Gaertner, D., Pagavino, M. and Marcano, J., 1999. Influence of fishers' behaviour on the catchability of surface tuna schools in the Venezuelan purse-seiner fishery in the Carribbean Sea. Can. J. Fish. Aquat. Sci. 56, 394-406.

Gillis, M.G., Peterman, R.M. and Tyler, A.V., 1993. Movement dynamics in a fishery: application of the ideal free distribution to spatial allocation of effort. Can. J. Fish. Aquat. Sci. 50, 323-333.

Hilborn, R. and Walters, C.J., 1987. A general model for simulation of stock and fleet dynamics in spatially heterogeneous fisheries. Can. J. Fish Aquat. Sci. 44, 1366-1369.

Maes, P., 1993. Behavioral-based artificial intelligence. In: From Animals to Animats 2. Proceedings of the Second International Conference on Simulation of Adaptive Behaviour, pp. 2-10.

Mangel, M. and Beder, J.H., 1985. Search and stock depletion: Theory and application. Can. J. Fish. Aquat. Sci. 42, 150-163.

Mangel, M. and Clark, C.W., 1983. Uncertainty, search, and information in fisheries. J. Cons. Int. Explor. Mer, 41, 93-103.

Millischer, L., 2000. Modélisation individu-centré des comportements de recherche des navires de pêche. Doctoral thesis. Ecole Nationale Supérieure Agronomique de Rennes. France, 246 pp.

Rijnsdorp, A. D., van Mourik Broekman, P.L. and Visser, E.G., 2000. Competitive interactions among beam trawlers exploiting local patches of flatfish in the North Sea. ICES Journal of Marine Science, 57, 894-902.

Salas, S., 2000. Fishing strategies of small-scale fishers and their implications for fisheries management. PHD Thesis, University of British Columbia. Vancouver, Canada. 154 pp.

Sampson, D. B., 1991. Fishing tactics and fish abundance, and their influence on catch rates. ICES J. Mar. Sci. 48, 291-301.

Van Oostenbrugge, J.A.E., van Densen, W.L.T. and Machiels, M.A.M., 2001. Risk aversion in allocating fishing effort in a highly uncertain coastal fishery for pelagic fish, Moluccas, Indonesia. Can. J. Fish. Aquat. Sci. 58 (8), 1683-1691.

Whitehead, S.D. and Lin, L.J., 1995. Reinforcement learning of non-Markov decision processes. Artificial Intelligence, 73, 271-306. 